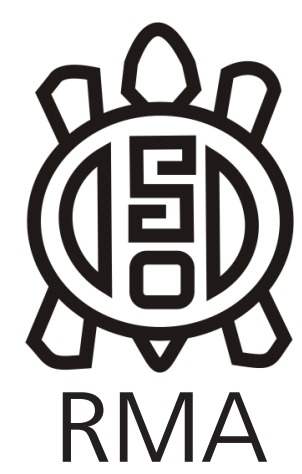

Dossier

\title{
Arte rupestre, agencia y ontología: Reflexiones actuales sobre el viejo animismo al sur de la Meseta Central de Santa Cruz. (Patagonia, Argentina)
}

\author{
Rock art, agency and ontology: Current reflections on the old animism
} south of the Central Plateau of Santa Cruz. (Patagonia, Argentina)

Raúl Eduardo Gonzalez Dubox*

*Laboratorio de Arqueología y Antropología. Instituto de Evolución y Diversidad Austral (CCT-CENPAT IDEAUS). E-mail: gonzalezdubox@cenpat-conicet.gob.ar

\begin{abstract}
Resumen
Analizar la agencia y ontología de la materia en restos arqueológicos plantea desafíos innegables y en ningún lugar estos desafíos son más agudos que en la interpretación del arte rupestre de Patagonia. Si bien la discusión en torno a la ontología de nuestros supuestos y categorías disfruta de un considerable lugar en la literatura antropológica y arqueológica, en los estudios de cazadores-recolectores patagónicos se mantienen principalmente al margen. En el presente ensayo exploro, sin pretensiones conclusivas, un modo de aproximarme a las manifestaciones rupestres de la Localidad Arqueológica La María al sur de la Meseta Central de Santa Cruz desde una perspectiva ontológica. Repasando crónicas de viajeros, descripciones etnográficas y recopilaciones de mitos, indago en la relevancia del concepto de ensamble de Fowler (2017) y animismo de Descola (2005), evaluando la posibilidad que motivos del repertorio rupestre como guanacos, felinos y negativos de manos, puedan ser abordados en términos de exterioridad/ interioridad-similitud/diferencia, retomando la noción de animismo como recurso interpretativo.
\end{abstract}

Palabras clave: Animismo; Ontología; Agencia; Arte Rupestre; Patagonia

\begin{abstract}
Analyzing the agency and ontology of matter in archaeological remains supose undeniable challenges, and nowhere are these challenges more acute than in the interpretation of the rock art of Patagonia. Although the discussion around the ontology of our assumptions and categories enjoys a considerable place in anthropological and archaeological literature, the studies of Patagonian hunter-gatherers remain mainly on the sidelines. In this essay I explore, without conclusive claims, a way of approaching to the La Maria rock art, in the south of the Central Plateau of Santa Cruz, from an ontological perspective. Reviewing travelers' chronicles, ethnographic descriptions and compilations of myths, I inquire into the relevance of the concept of assembly by Fowler (2017) and animism by Descola (2005), evaluating the possibility that motifs from the rock repertoire such as guanacos, felines and negatives of hands can be approached in terms of exteriority / interiority-similarity / difference, taking up the notion of animism as an interpretive resource.
\end{abstract}

Keyword: Animism; Ontology; Agency; Rock Art; Patagonia

"Sospechamos de lo sagrado y de los nombres que se le dan o han dado. Estamos a la defensiva de la superstición, de la magia, de proyecciones inconscientes (...) $Y$ asi para muchos aparece como una mentira vital, un retorno a lo primitivo" Cesar, R. 1984

Introducción: Animismo, ensambles y agencia

Existe una relación de continuidad entre personas, cosas y mundo. Una relación mutuamente constructiva, donde cada parte tiene la capacidad de intervenir en el todo. Históricamente la capacidad de intervenir en la vida humana que tienen las "cosas" o los "lugares", fue asociada a creencias y prácticas animistas, consideradas formas fantasiosas de explicar la realidad. Si bien originalmente fue definido como una creencia generalizada en un espíritu o alma 'animadora' (Tylor, 1871), los debates actuales resignifican la noción, superando concepciones estrechas y dicotómicas propias de la modernidad y reconociendo agencia en la materia (Latour, 2012; Bodei, 2013). Precisamente, el resurgimiento del interés en el animismo ha incluido su reformulación como un tipo de ontología relacional (Ingold, 2000), manifestando un interés en comprender 
la lógica de la agencia de los objetos en otras culturas.

Descola (2005) sugiere que la experiencia de relacionarse con la "naturaleza" se puede explicar mediante la aceptación o negación en otros seres u objetos, de una interioridad (intencionalidad, subjetividad, reflexividad, afecto) y una exterioridad (forma, sustancia, procesos fisiológicos, perceptivos, sensoriales y motores), y el reconocimiento de similitudes y diferencias con aquellas. Así, a partir de las posibilidades de similitud y diferencia de exterioridad e interioridad, las relaciones humanos/nohumanos se articulan en cuatro esquemas, que consisten en animismo (interioridad semejante, exterioridad diferente), naturalismo (interioridad diferente, exterioridad semejante), totemismo (interioridad y exterioridad semejante) y analogismo (interioridad y exterioridad diferente). Sin duda la identificación de estos esquemas en el registro arqueológico es un desafío enorme, que si bien en otras latitudes existen antecedentes que han explorado a partir del registro cerámico y del arte rupestre (Laguens, 2009; Laguens \& Gastaldi 2008; Troncoso, 2014), en el caso de Patagonia es novedosa.

Si bien diversos estudios abocados al arte rupestre en Patagonia hablan del carácter activo del arte rupestre, en cuanto a su función comunicativa y su participación en el intercambio y circulación de información (Acevedo, 2017; Carden, 2007; Fiore, 2020; Gonzalez Dubox et al., 2021; Guichón, 2018; Re, 2010; entre otro) la discusión sobre el carácter ontológico del arte rupestre, continua gravitando en el rol de mediación pasiva, atribuida por agentes humanos.

Pensar el status ontológicamente activo para el arte, implica asumir su agencia intrínseca, al margen de la solidaridad de la mente humana. El problema de definir la agencia está íntimamente relacionado con el problema de definir lo humano y de las relaciones entre una persona individual y todas y todo lo demás que la rodea (Gardner, 2004). La amplia diversidad de definiciones de agencia, coinciden en que la diversidad de definiciones de agencia, el término implica "poder sobre", es decir, la capacidad de afectar lo que otra persona hace, y "poder para", la capacidad básica de hacer algo (Dowding, 1996; Dobres \& Robb, 2005; entre otros). En los últimos años se ha enfatizado el valor de un enfoque relacional de la agencia, en lugar de uno que trate el concepto como una propiedad individual (Gardner 2004; Ingold 2000). El concepto de "agencia" enfatiza el conflicto, la contradicción, los significados y la importancia de la historia (Jordan, 2004). La agencia es social y no exclusivamente individual o mental, en la medida que se inserta en un medio de relaciones encadenando acciones, afectos y efectos entre agentes humanos y no-humanos (Gell, 2016). Gell (2016) sugiere que todo objeto o persona materializan capacidades agentivas, colocándose en posición e agentes en situaciones y contextos determinados ${ }^{1}$.

¿Cómo indagar arqueológicamente en esa propiedad de poder sobre y poder para de los imágenes rupestres? ¿Qué herramientas teóricas y metodológicas tenemos disponibles para esta tarea? Alberti y Marshall (2009) sugieren que todas las propiedades, son propiedades de las cosas-en-relación, no de las cosas ${ }^{2}$ mismas. Más que hechas de objetos discretos o piezas de materia, todas las cosas están constituidas por relaciones. Seguro nos resulta familiar la idea de recuperar las relaciones entre los materiales que se encuentran en un sitio arqueológico, ya que la misma definición de contexto arqueológico se concibe relacionalmente (Aschero, 1988). Los objetos se ponen en relación como parte del contexto, pero no por su propia capacidad relacional, como si los objetos fueran puestos en relacionan mediante observaciones de asociación y proximidad (Laguens, 2014). Esta reflexión en torno al contexto arqueológico es particularmente relevante para los conjuntos de pinturas donde evidentemente no hay factores tafonómicos (al margen de la conservación diferencial) que estén incidiendo en la asociación y distribución de los motivos. Hay relaciones intrínsecas, algo en los atributos de las imágenes y soportes que moviliza dichas asociaciones.

Para describir esa constelación de relaciones, recurro a la noción de ensamble de Fowler (2017), definida como una disposición específica de componentes diversos, heterogéneos e interactivos que tiene efectos específicos, que actúa de una manera que ninguno de sus componentes puede hacerlo sin estar en tal configuración. No tiene un único punto de origen ni un principio organizador singular, sino que resulta de relaciones, procesos y eventos múltiples y sucesivos. Sus propiedades y efectos emergen contingentemente. Dicha noción resulta útil para pensar las manifestaciones rupestres como un ensamble de atributos humanos y no-humanos y evita partir del supuesto que las pinturas rupestres constituyen la dimensión pasiva de un proceso ontológicamente unidireccional que va desde el pintor/ observador a la imagen, desde lo activo a lo pasivo. De esta forma la acción de pintar se lleva a cabo junto con otras agencias activas, que pueden incluir la agencia del soporte, de la materialidad de la pintura y del color, del motivo, de los motivos adyacentes, de la persona que mira y aquellas que estuvieron previamente. La agencia puede considerarse como una propiedad de la misma red de relaciones que constituyen las entidades (Alberti

\footnotetext{
1 Dado que excede los objetivos de este articulo ofrecer una presentación detallada de las discusiones actuales en torno a la noción de "agencia", para enriquecer la reflexión de esta problemática se sugiere la lectura de Alfred Gell (1998) "Arte y Agencia: una teoría antropológica" traducido al español por Editorial SB (2016) y de Andrew Gardner (2004) "Agency Uncovered Archaeological perspectives on social agency, power".

2 Bodei, R. (2013) utiliza la noción de cosa, para evitar hablar de objetos por un lado y sujetos por el otro. A su vez, permite incorporar fenómenos, seres e ideas que son difíciles de incluir dentro de la noción de "objeto".
} 
y Jones, 2013; Gardner, 2004; Laguens, 2009).

A continuación, exploraré, sin pretensiones conclusivas, un modo de aproximarme a las manifestaciones rupestres patagónicas desde una perspectiva ontológica. Indago en la relevancia del concepto de ensamble de Fowler (2017) y animismo de Descola (2005), en el estudio arqueológico de las relaciones entre humanos, no humanos, imágenes y paisajes en la Localidad Arqueológica La María al sur de la Meseta Central de Santa Cruz, con el objetivo de abordar el repertorio rupestre de la localidad, en diálogo con los estudios de las llamadas arqueologías pos interpretativas, que comparten un interés común por ir más allá de la interpretación de los significados o funciones. La idea central es atender a las múltiples interconexiones, tanto materiales como inmateriales, que pueden existir entre los motivos rupestres, los espacios, la materialidad y las personas con la finalidad de enriquecer las reflexiones actuales sobre las sociedades pasadas que habitaron la localidad. Para esto buscare en el repertorio la presencia de motivos que puedan ser abordados en términos de exterioridad/interioridad-similitud/diferencia, retomando la noción de animismo como recurso interpretativo, y evaluare sus atributos en función de ensambles.

\section{Antecedentes}

\section{Magia primitiva y abandono}

Si bien la discusión en torno a la ontología de nuestros supuestos y categorías disfruta de un considerable lugar en la literatura antropológica y arqueológica, los estudios de cazadores-recolectores se mantienen al margen (Jordan, 2004). Así mismo, el arte rupestre, ha sido poco frecuentado por un pensamiento que discuta las bases ontológicas del saber arqueológico. Los estudios fundacionales relacionaron el arte rupestre con ceremonias de iniciación, hechizos de caza o fertilidad, asignándoles un sentido mágico-religioso (Reinach, 1903; Jordan, 2004). Inicialmente en Patagonia, un tema de interés de la arqueología Histórico Cultural fue la búsqueda de paisajes sagrados (Menghin, 1952; Schobinger, 1956; Molina, 1976) y la descripción de rituales y mitologías.

Menghin señalaba que, "el hombre primitivo" cree en una identidad mistica entre el objeto y su imagen, que también acontece al original todo lo que le ocurre a la imagen... las escenas de caza de guanacos también pueden interpretarse como hechizos de caza..." (Menghin, 1952, p 19). Schobinger (1956), por su parte, con el fin de reconocer espacios sagrados y ámbitos mágico-espirituales, analizó la orientación espacial, posición, emplazamiento y topografía de los lugares con arte rupestre. Planteó que la elección de un lugar para pintar no dependía sólo de condiciones para la subsistencia sino también de otros factores vinculados con su dimensión espiritual y destacó el impacto que diversos paisajes tienen en la subjetividad humana, en función de la sensibilidad de los cazadores recolectores frente a las fuerzas de la naturaleza. Asimismo, Schobinger y Gradin, en referencia al arte rupestre, afirman que "...se trata de una forma simbólica de expresar ideas y vivencias surgidas de la esfera mágico-religiosa..." (Schobinger y Gradin, 1985 p 7). Igualmente, Casamiquela detalló relaciones entre estilos rupestres, decoración textil y mitología tehuelche-mapuche. Realizó numerosos estudios de las lenguas, mitologías y religiones de las sociedades indígenas patagónicas, a ambas vertientes de la Cordillera de los Andes (Casamiquela, 1958, 1960). Recopiló canciones totémicas ${ }^{3}$, que se desarrollan durante bailes, donde los participantes se ponen (literal y figurativamente) en la piel de animales tales como el ñandú, el guanaco, el zorro o el puma (Casamiquela, 1958).

Estas citas enseñan una preocupación por explicaciones mágico-religiosas, pero también evidencian el ordenamiento del mundo de los autores dentro de una ontología cartesiana moderna, al entender la materialidad y vitalidad de las cosas como separadas, donde es la mente humana la que se solidariza con las cosas para atribuirles vida (interioridad). Si bien fue inaugural, las nociones de magia y animismo en los estudios de arte rupestre patagónico, fueron perdiendo terreno paulatinamente. No es el objetivo de este ensayo profundizar en la explicación del abandono de las inquietudes animistas, pero se puede decir que la principal crítica al animismo abrevó en postulados propios de la modernidad: los objetos no tienen agencia, por lo tanto, creer que pueden estar "vivos", se considera como mínimo una fantasía incomprobable desde la materialidad del registro arqueológico.

En este sentido, primero la arqueología Histórica Cultural, se interesó en el animismo desde una ontología cartesianamoderna, entendiendo la vitalidad de la materia como una epistemología equivocada y posteriormente la arqueología procesual recurrió a las referencias etnográficas como fuente de analogías para la vida pasada y para enriquecer el debate teórico (Alberti y Jones, 2009). Un aporte importante desde el procesualismo fue concebir el arte rupestre como un artefacto más e interpretarlo en relación a las estrategias de movilidad y de asentamiento de las sociedades cazadores-recolectores, pero sin cuestionar el status ontológico de las imágenes rupestres. Esta perspectiva motivo diversos trabajos que se centraron en una aproximación a la funcionalidad del arte rupestre (Wobst, 1977; Aschero, 1988, 1996 entre otros). Sin embargo, la búsqueda de los aspectos funcionales en el arte rupestre, implicó un abandono de la búsqueda de la dimensión simbólica, inmaterial y espiritual (Carden, 2007). Posteriormente, la arqueología Posprocesual, puso en un segundo plano la preocupación por la funcionalidad

3 Cabe aclarar que la asignación de totémicas responde a criterios del mismo autor (Casamiquela 1958), no necesariamente coincide con los criterios propuesto por Descola (2005) para reconocer este esquema ontológico. 
del arte rupestre y centro su interés en los significados y el simbolismo, dejando de lado la materialidad. La inquietud por la agencia de la materia va a cobrar un lugar protagónico en las arqueologías simétricas, no representacionales y particularmente aquellas que se identifican afines al giro ontológico (Alberti, 2016).

\section{El espacio y el arte rupestre}

En arqueología las relaciones humano-cosa-espacio son de particular interés. En el caso del arte rupestre, su estrecha vinculación con la topografía del entorno es definitoria para numerosos autores (Laming Emperaire, 1962; Leroi-Gourhan 1965; Schobinger y Gradin, 1985; Hartley, 1992; Criado Boado, 1999; Acevedo, 2017; Acevedo et al., 2013; Acevedo \& Fiore, 2020 entre otros). Numerosos casos etnográficos dan cuenta de esta red de relaciones entre objetos personas y espacios.

Los Khanty ${ }^{4}$ consideran que el paisaje está habitado por humanos vivos, difuntos y seres divinos, cuyas presencias en lugares clave informa los patrones de territorialidad humana y la adquisición de recursos a largo plazo (Jordan, 2004). La existencia diaria es inestable, no porque no estén capacitados en sus actividades de subsistencia, sino porque los recursos que obtienen del mundo pertenecen a otras agencias no-humanas. Cada persona Khanty está unida a una intrincada red de relaciones y obligaciones con seres divinos, que ayudan, protegen y apoyan. La comunión con ellos es vital, y para abrir canales de comunicación, las ofrendas materiales deben hacerse con bienes alterados por la agencia humana, y depositadas en puntos determinados del paisaje, considerados sitios sagrados (Jordan, 2004). Igualmente, Tilley propone un dialogo ritual como explicación de los alces grabados en los sitios de Nämforsen ${ }^{5}$ (Tilley, 1991). La comunidad ha tomado comida del mundo y grabar alces en sitios específicos, es una forma de ofrecer algo a cambio, un cumplimiento de obligaciones recíprocas, una forma de informar a las agencias espirituales que se siente gratitud por los alces que han sido adquiridos.

En el mundo andino, ciertos lugares y objetos tienen necesidades consideradas humanas, tales como ser alimentados, respetados, recordados y visitados. Las huacas son alimentadas mediante ofrendas y recordadas mediante visitas cíclicas. Se entabla una relación en función de una similitud interior entre humanos y entidades no humanas (Nazar y De la Fuente, 2016). En Patagonia, al sur de Neuquén en el paraje Ali Curá, Casamiquela (1977) presenta testimonios etnográficos de las piedras sagradas con ojos, bloques emplazados

4 Los Khanty son una comunidad siberiana de cazadores-recolectores seminómadas, de las pocas de latitudes altas para las cuales existen datos etnográficos y etnohistóricos detallados sobre el uso ritual del espacio (Jordan, 2003).

5 Sitio arqueológico con numerosos grabados rupestres, ubicado en el norte de Suecia, en el área del río Ångerman. Corresponde a comunidades de cazadores-pescadores-recolectores que habitaron el área entre 3000 y 1500 a. C. (Tilley, 1991) en lugares particulares del paisaje, que tienen alrededor de un metro de altura, con huecos (algunos naturales otros antrópicos) donde los viajantes dejan ofrendas para augurar buen viaje, lo que se conoce como rito giratorio, que pueden propiciar el bien o el mal. La roca se comporta como una huaca, con necesidades humanas de alimento, afecto y compañía, necesidades con las que se dialoga a través de la ofrenda y las visitas periódicas.

Alberti (2016) sostiene que, ante un mundo dinámico, cambiante, inestable, una forma de contrarrestar esa inestabilidad es fijar las cosas a través de la materialidad: Tatuar los cuerpos es identificarlos y lograr que no cambien; copiar las cestas en arcilla es lograr su durabilidad; hacer durante siglos las mismas cosas es aparentar estabilidad, que el tiempo no pasa (Laguens, 2018), de forma tal que los materiales en sí mismos también participan de procesos de generación y regeneración del mundo, el cual se halla en constante fluir (Alberti, 2016). Esas cosas también son inestables; están sujetas al mismo fluir del mundo. La clave entonces está en las prácticas: se trata de prácticas estabilizadoras. Desde esta perspectiva, la comprensión de las pinturas no trataría solo de un estudio de la sintaxis relacional dentro del ensamble de motivos rupestres, sino de la sintaxis de la praxis de pintar, que ubica el motivo, el panel y el sitio dentro de un ensamble más amplio, y los actos de pintado y contemplación dentro de la biografía de imágenes, individuos y comunidades.

\section{Área y caso de Estudio}

\section{El Arte Rupestre de La María}

La localidad arqueológica de La María se encuentra a unos $150 \mathrm{~km}$ al noroeste de la localidad de Puerto San Julián, al sur de la Meseta Central de Santa Cruz (Fig. 1). Al margen de algunas visitas breves (Gonzalez, 2000; Molina, 1976), las primeras menciones explícitas del arte rupestre de La María son realizadas por Cardich (1979) en el marco de sus investigaciones en El Ceibo, localidad lindera a la misma. El primer trabajo con foco en las pinturas de la localidad es la tesis doctoral de Jean-Marie Franchomme, en la cual realiza, a mediados de la década de 1980, un relevamiento inicial del área en busca de sitios con pinturas (Franchomme, 1991). El conocimiento en mayor profundidad de La María se lo debemos al trabajo de Rafael Paunero y colaboradores (Paunero, 2000; 2009; Paunero et al., 2005, Skarbun, 2009; Frank, 2011; Cueto, 2015; Valiza Davis 2021, entre otros).

Los sitios de la localidad están inmersos en un paisaje con topografía diversa que ofrece una alta visibilidad arqueológica, con alturas variables, mesetas elevadas, cañadones, numerosos bajos $\mathrm{y}$, particularmente, una gran cantidad de cuevas, aleros y reparos. También se encuentran recursos como agua, leña, materias primas líticas de excelente calidad y fuentes de pigmentos y yeso para hacer pinturas, diversidad que llevó a dividir la 


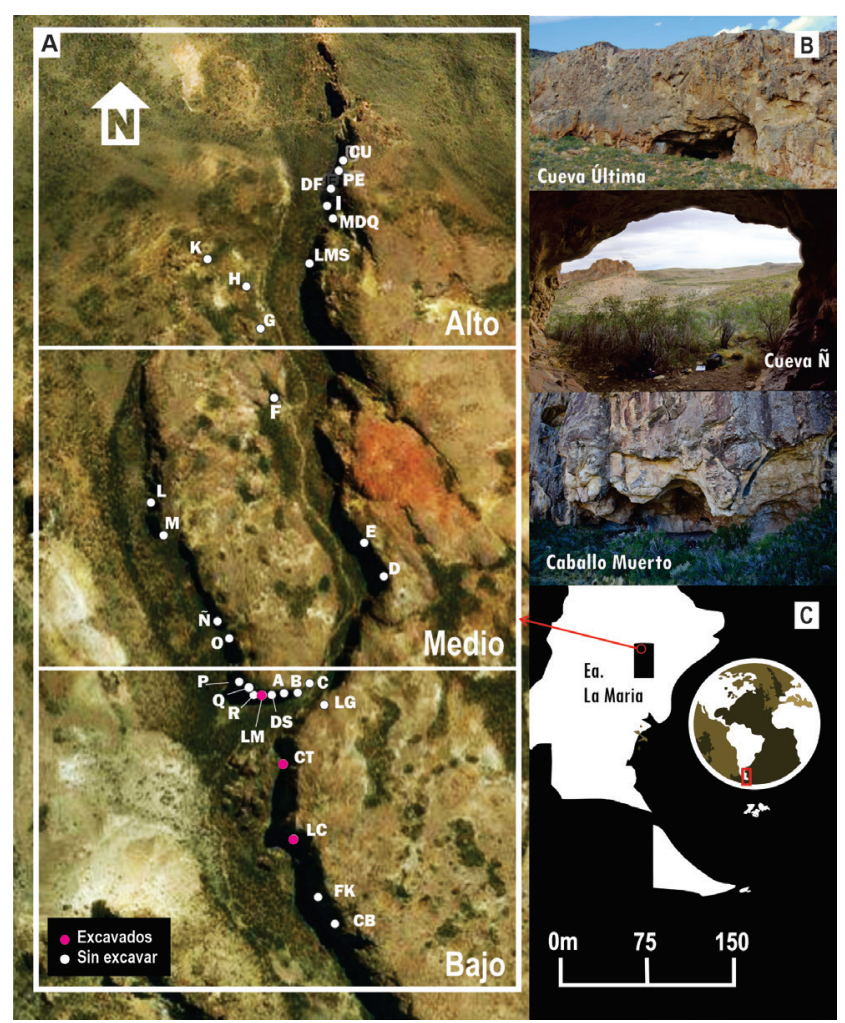

Figura 1. Sector La María Quebrada. A. Localización de los sitios con pinturas rupestres. Sitios con estudios estratigráficos: LC, La Cocina; CT, Cueva Túnel y LM, La Mesada. B. Vista de las cuevas, C. posición de la localidad en la Prov. de Santa Cruz y escala del mapa del sector.

Figure 1. La María Quebrada sector. A. Location of the sites with cave paintings. Sites with stratigraphic studies: $L C, L a$ Cocina; CT, Cueva Túnel and LM, La Mesada. B. View of the caves, $C$. position of the locality in the province of Santa Cruz and scale of the map of the sector.

localidad en 13 sectores. El relevamiento realizado hasta el momento muestra que todos los motivos rupestres corresponden a pinturas se han identificado 77 cuevas con motivos pintados (Paunero 2000, 2009; Paunero et al. 2005, Gonzalez Dubox, et al. 2021). La abundancia, densidad y diversidad de pinturas es llamativa y distintiva de la localidad. Me enfocaré en el arte rupestre del sector La María Quebrada, ubicado al norte de la localidad, constituido principalmente por afloramientos de ignimbrita que delimitan en sentido norte-sur, un cañadón profundo que discurre entre una zona baja, que actúa como bajo recolector de aguas y una porción alta al pie de un manto de basaltos, diferencia de altura que permitió definir tres segmentos identificados como alto, medio y bajo. En este sector se identificaron 29 sitios con 1590 motivos rupestres (Gonzalez Dubox et al, 2021).

El repertorio rupestre consiste en motivos figurativos, no figurativos e indeterminados (Tabla 1). El conjunto no figurativo $(n=989 ; 62,20 \%)$ es el más abundante en los tres segmentos del sector LMQ. Dentro de este grupo destacan por su cantidad y diversidad las líneas, circunferencias y círculos, ambos presentes en mayor medida en el segmento bajo. Los motivos figurativos son marcadamente menos abundantes ( $n=545 ; 34,28 \%)$. No obstante, el motivo más frecuente en todo el repertorio corresponde al tipo mano ( $n=402 ; 25,28 \%)$. Destacan las numerosas y diversas imágenes de guanacos, tanto aislados como en escenas, que en algunos casos involucra antropomorfos (Gonzalez Dubox et al, 2021). Un tipo de motivo poco frecuente pero llamativo corresponde a las imágenes alusivas a felinos, algunas a través de la pintura naturalista de felinos enteros y otras insinuadas a través de la representación esquemática de alguno de sus atributos como puede ser la pigmentación del pelaje o sus pisadas. En relación a los colores, el más abundante es el rojo y sus diversas tonalidades. También se reconocen negros, blancos, amarillos, naranjas y rosas.

A continuación, me enfocaré en tres posibles ensambles en relación a tres tipos de motivos llamativos y sumamente relevantes en los repertorios de arte rupestre patagónico: los negativos manos, los guanacos y las imágenes afines a los felinos. Estos motivos, sus atributos de emplazamiento, posición, color y asociaciones y los espacios que ocupan, serán abordados en relación a menciones etnohistóricas y etnográficas, que me serán útiles para presentar reflexiones e interrogantes sin pretensiones concluyentes que se enmarcan dentro de la perspectiva de las llamadas arqueologías del giro ontológico.

\section{Caso I: Ensamble cueva-manos}

La totalidad de las manos pintadas $(n=402)$ presenta una gran diversidad en cuanto a las características de los soportes, así como los atributos de visibilidad, color, emplazamiento y relación con otros motivos (Fig. 2). La totalidad de las manos fue registrada en cuevas $^{6}$. Los abrigos rocosos de dimensiones muy grandes, que permiten la presencia simultánea de grupos numerosos de personas y una amplia visibilidad del entorno, agrupan el $64,42 \%$ de las manos. Casi el $75 \%(n=301)$ del subconjunto se encuentra asociado con otro motivo, generalmente a otras manos, a veces superpuestas, alineadas entre sí o formando grandes conjuntos pero también a otros elementos tales como guanacos, soles, puntos, líneas o circunferencias. Se reconocen manos de diversos tamaños y a diferentes alturas del suelo. Si bien la mayoría de las manos se encuentran emplazadas en las paredes de los abrigos, algunas aparecen emplazadas en el techo o en paneles colgantes que exceden la altura media de una persona adulta, lo que implica el uso de "andamios" y/o la asistencia de otras personas a la persona que pinte. En este sentido son interesantes las manos de infantes a alturas que superan la de un niño o niña, señalando una actividad colectiva donde estarían participando varias personas. La forma de la mano pintada depende, en la mayoría de los casos de LMQ, de una

6 No descartamos la posibilidad que se hayan pintado espacios sin reparo, y que la acción diferencial de la meteorización, provoque un sesgo en la distribución actual. 


\begin{tabular}{|l|c|c|c|c|c|c|c|c|}
\hline \multirow{2}{*}{ Motivos } & \multicolumn{2}{|c|}{ Alto } & \multicolumn{2}{c|}{ Medio } & \multicolumn{2}{c|}{ Bajo } & \multicolumn{2}{c|}{ Total } \\
\cline { 2 - 9 } & $\mathbf{n}$ & $\%$ & $\mathrm{n}$ & $\%$ & $\mathrm{~N}$ & $\%$ & $\mathrm{~N}$ & $\%$ \\
\hline No figurativo & 240 & 24,3 & 95 & 9,61 & 654 & 66,1 & 989 & 62,2 \\
\hline Punto & 24 & 26,09 & 14 & 15,22 & 54 & 58,7 & 92 & 5,79 \\
\hline Linea & 85 & 21,96 & 26 & 6,72 & 276 & 71,32 & 387 & 24,34 \\
\hline Trazo & 16 & 24,24 & 7 & 10,61 & 43 & 65,15 & 66 & 4,15 \\
\hline Franja & 2 & 8,33 & 2 & 8,33 & 20 & 83,33 & 24 & 1,51 \\
\hline Arrastre & 3 & 100 & & & & & 3 & 0,19 \\
\hline Círculo & 15 & 23,08 & 5 & 7,69 & 45 & 69,23 & 65 & 4,09 \\
\hline Circunferencia & 54 & 21,01 & 29 & 11,28 & 174 & 67,7 & 257 & 16,16 \\
\hline Óvalo & 38 & 48,72 & 8 & 10,26 & 32 & 41,03 & 78 & 4,91 \\
\hline Asterisco & & & & & 3 & 100 & 3 & 0,19 \\
\hline Estarcido indet. & 1 & 25 & 3 & 75 & & & 4 & 0,25 \\
\hline $\begin{array}{l}\text { Oquedad } \\
\text { Pintada }\end{array}$ & 1 & 100 & & & & & 1 & 0,06 \\
\hline Figura indet. & 1 & 11,11 & 1 & 11,11 & 7 & 77,78 & 9 & 0,57 \\
\hline Figurativos & 118 & 21,7 & 57 & 10,5 & 370 & 67,9 & 545 & 34,28 \\
\hline Antropomorfo & 3 & 75 & & & 1 & 25 & 4 & 0,25 \\
\hline Felino & 1 & 100 & & & & & 1 & 0,06 \\
\hline Guanaco & 34 & 49,28 & 20 & 28,99 & 15 & 21,74 & 69 & 4,34 \\
\hline Escena & 9 & 52,94 & 6 & 35,29 & 2 & 11,76 & 17 & 1,07 \\
\hline Mano & 52 & 12,94 & 30 & 7,46 & 320 & 79,6 & 402 & 25,28 \\
\hline Pisada & 13 & 35,14 & 1 & 2,7 & 23 & 62,16 & 37 & 2,33 \\
\hline Sol & & & & & 8 & 100 & 8 & 0,5 \\
\hline Zoomorfo indet. & 6 & 85,71 & & & 1 & 14,29 & 7 & 0,44 \\
\hline Indeterminado & 12 & 21,43 & 7 & 12,5 & 37 & 66,07 & 56 & 3,52 \\
\hline Total & 370 & 23,3 & 159 & 10 & 1061 & 66,7 & 1590 & \\
\hline
\end{tabular}

Tabla 1. Frecuencias y porcentaje de tipos de motivos figurativos, no figurativos e indeterminados por segmentos del sector LMQ.

Table 1. Frequencies and percentage of types of figurative, non-figurative and indeterminate motifs by segments of the $L M Q$ sector.

técnica muy particular, que es el negativo por estarcido (Fig. 3a, b y c). Dicha técnica consiste en aplicar pintura mediante un soplo (Paunero, 1992; Blanco, 2015; Blanco \& Carden 2016). Además de una serie de pasos previos (obtención pigmentos, molienda, aplicación del diluyente, etc.), la aplicación requiere sostener la pintura cierto tiempo en la boca, cambio de temperatura, y mezclado con saliva. Una vez que la pintura alcanza la textura y temperatura ideal se sopla, se escupe sobre la mano apoyada en la roca (Paunero, 1992; Blanco, 2015).

Estas descripciones, invitan a pensar a los negativos de manos como un ensamble de propiedades de múltiples cosas que se articulan: personas, cueva, pintura, animales, espacios, objetos, artefactos, técnicas, conocimientos, agencias, etc. ¿Qué atributos pueden ser considerados parte del negativo de mano? Muster ${ }^{7}$ describe una ceremonia tehuelche para curar a un niño enfermo, que consistía en realizar marcas con las manos en color ocre sobre una yegua de color blanco. Describe a su vez la presencia de objetos que oficiaban de amuletos y palabras específicas recitadas (Muster, 1871 [2016]; p.247). Esta observación de Muster, hace referencia a los atributos de la mano asociados a la salud y la perpetuación de la vida. Cesar (1984) por su parte distingue: "...el negativo de mano de la cueva (...). Acaricia golpea, arrebata, estrangula, apoya, ataca, defiende, moldea, construye, imita, recoge, dona, cura, consuela, hace cosquillas, tapa las heridas, reza y también puede pintarse a si misma..." (Cesar 1984, p. 62).

\footnotetext{
7 Recurro a la crónica histórica sólo con fines reflexivos ya que un motivo tan extendido en el tiempo como los son los negativos de manos, seguramente haya sido asociado a múltiples atributos a lo largo de la historia del arte rupestre patagónico. Tampoco puedo dejar de señalar el sesgo que implica la mirada de los cronistas en la descripción de los hechos que observaban.
}

De esta forma el ensamble mano-cueva cueva implica pensar juntos los atributos señalados para la mano, con aquellos propios de los abrigos rocosos, como estabilidad, fortaleza, refugio, profundidad. En este sentido, Aberti (2014) plantea que el mundo y los materiales (y las imágenes) son inestables y son las prácticas las que proveen estabilidad, entonces el hecho de pintar las manos en las cuevas quizás pueda ser leído como una forma de sostener, de afirmar el mundo, hecho que podría asociarse a la recurrencia con la que aparecen pintadas (Fig. 2d). La noción de territorialización (Lucas, 2012), indica como un ensamble de estas características adquiere agencia y produce efectos y uno de esos efectos cual podría ser reafirmar "lo colectivo" de las huellas de manos. Otro efecto de la territorialización es la perduración en el tiempo: mientras las cosas estén unidas, estén ensambladas, el efecto territorializador sigue funcionando. Retomando la idea de huaca mencionada anteriormente, como un lugar que tiene necesidades de alimento y visita y los atributos humanos que puede corporizar los negativos de mano, los lugares donde se concentran estas imágenes podrían estar asociados a espacios que participan de formas más activas en la estabilidad del mundo y en la perpetuación de la vida: las cuevas con manos (Fig. 3d).

\section{Caso II: el ensamble guanaco-humanos}

El guanaco aparece en el registro arqueológico de La María de múltiples formas, tanto como recurso que participa en la dieta de los pobladores del área, como materia prima para la elaboración de artefactos (Paunero et al. 2010; Paunero y Valiza Davis 2013; Valiza Davis 2021). En el repertorio, aparecen pintados con diferentes técnicas, colores, emplazamientos y asociaciones. En general se registró la figura del guanaco, la silueta que hace referencia a su cuerpo, su exterioridad, a diferencia 


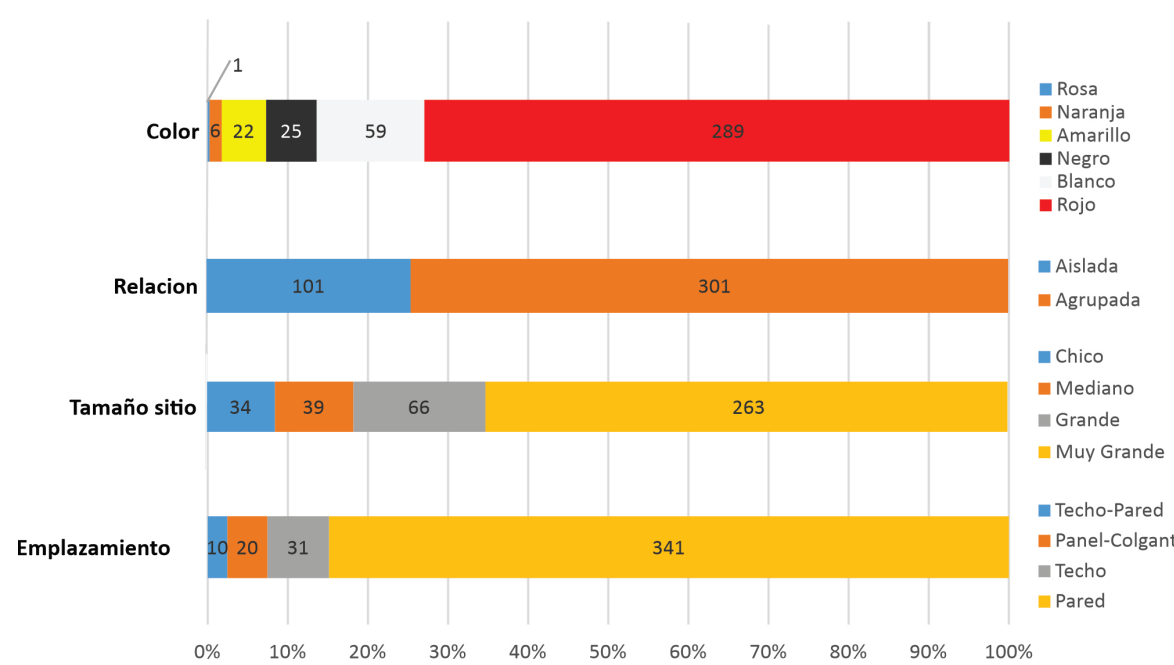

Figura 2. Tipo de motivo mano, frecuencias y porcentajes en función de características consideradas.

Figure 2. Type of hand motive, frequencies and percentages depending on the characteristics considered. de otros animales como el choique o felino, que son más comunes sus huellas que los cuerpos $^{8}$. Si bien se registran guanacos aislados en situación estática $(n=68)$, la mayoría aparecen agrupados junto a otros guanacos alineados o dispersos, asociados mediante vínculos anecdóticos en los cuales se puede reconocer cierta narrativa $(n=108$, Tabla 2), mostrando tropillas corriendo sobre la topografía del soporte o tomando agua con las cabezas disimuladas en el círculo que constituye la fuente agua (Gonzalez Dubox et al., 2021). Frecuentemente se asocian a no figurativos, en particular a circunferencias (Fig. 4.1 a) y líneas (Fig. 4.1 b).

Troncoso (2014) al abordar el arte rupestre de cazadores recolectores del norte semiárido de Chile señala una exclusividad de motivos no figurativos y ausencia de motivos antropomorfos o zoomorfos y afirma que esta ausencia no es accidental, sino que da cuenta de un elemento central del esquema ontológico cazadorrecolector: una falta de diferenciación ontológica entre la apariencia humana y la animal. En el caso de LMQ, esta indiferenciación no parece tan marcada, ya que entre los motivos figurativos se han reconocido figuras humanas y de guanacos (Tabla 2). Si bien las imágenes de guanacos asociadas con antropomorfos son pocas, son emblemáticas las escenas de caza o los guanacos enlazados, así como negativos de manos superpuestos a guanacos (Gonzalez Dubox et al., 2021). En dos escenas se reconoció la presencia simultánea de figuras antropomorfas y guanacos. $Y$ en dos escenas figuran guanacos enlazados, dando a entender la presencia tacita de seres humanos (Tabla 2).

Las diferentes imágenes alusivas a humanos y no humanos, me lleva a pensar en una diferenciación de la exterioridad entre humanos y no humanos ¿Indicará esta diferencia una distinción en el status ontológico que recibía el guanaco frente a los humanos? Como ontología animista deberíamos reconocer, además de la diferencia de exterioridad, una similitud de las interioridades

8 Podríamos decir lo mismo de los humanos, ya que son más frecuentes sus manos (huellas) que sus cuerpos enteros.
(Descola, 2005). Para evaluar la interioridad, tenemos muy pocos elementos. Anteriormente, mencionamos las canciones totémicas que describe Casamiquela como una posible fuente para reconocer similitud de interioridad con atributo de guanacos $u$ otros animales. Casamiquela recopiló 34 canciones a través de dos informantes claves Guena kena hablantes, pobladores de la provincia de Chubut: José María Cual, nieto de Faquico León, habitante de Gangan y Doña Nahueltripay, sobrina de Sayhueque, pobladora del paraje alto Ñorquinco, en las inmediaciones de Cushamen (Casamiquela 1958). En las rogativas araucanas las mujeres entonan cánticos propios de los tótems (Kempen) de los bailarines varones durante el lonkomeo, descrito como un baile pantomímico donde los bailarines se ponen (literal y figurativamente) en la piel de animales tales como el ñandú, el guanaco, el zorro o el puma. El tótem puede provenir de cualquier reino de la naturaleza, tanto animal, vegetal como geográfico, y cada kempen tiene su canción. Las canciones totémicas se caracterizan por la descripción detallada que revela profundidad en la observación y un tono admirativo con respecto al tótem. La canción del guanaco es descripta como "con vida y ritmo propio... cuyo compás imita y evoca el galope y salto de las bestias..." (Casamiquela, 1958; p294). La canción del guanaco ${ }^{9}$ particularmente, hace referencia al posible gozo que siente el guanaco al trotar por la "tierra de pintura" (¿pigmentos?).

¿Sera la identificación de una interioridad, una capacidad de gozo del guanaco similar a la humana, al identificar lugares agradables para circular? En cuanto al arte, si bien podemos concluir que los guanacos muestran un tratamiento preferencial de la exterioridad y una diferenciación con la figura humana, no reconozco indicadores concluyentes para pensar la interioridad. Podemos pensar en un sesgo cronológico, ya que los repertorios rupestres actuales pueden estar agrupando formas de pintar a lo largo del tiempo relativas a

9 "Trahaile (onomatopeya del guanaco) Goza (la palabra más cercana que encuentra el autor al momento de traducir) Es linda la tierra de pintura (colorada), para andar al trote, bonito cara tordilla" (traducción de Casamiquela, 1958 p. 306) 




Figura 3. Tipo de motivo Mano. A. y b. Negativos de mano, Cueva A, fotografía original; C. Positivo de mano, Cueva $\tilde{\mathrm{N}}$, fotografía original y D-Strech, yre. D. Cueva LC, negativos de mano en diferentes posiciones, orientaciones, alturas y colores, D-Strech, Ire.

Figure 3. Type of motif Hand. A. and b. Hand negatives, Cave $A$, original photograph; C. Positive hand, Cueva N, original photograph and D-Strech, yre. $D$. Cave $L C$, hand negatives in different positions, orientations, heights and colors, D-Stretch, Ire. esquemas ontológicos diferentes y que en la actualidad se presenten como un conjunto indiferenciado.

\section{Caso III: Ensamble felinos-antropomorfos}

En todo el continente Americano se registran testimonios sobre estrechos vínculos espirituales, afectivos y cognitivos entre personas y felinos y en especial los jaguares (Panthera onca). La imagen del felino ocupó y ocupa un lugar importante en la representación visual de ritos y creencias de numerosos pueblos americanos. (Gonzalez, 1998; Pastor et al., 2015; Paunero, 2009). En el arte rupestre patagónico las imágenes de felinos son escazas. Son emblemáticos los descritos por Arrigoni (1996) para La Reconquista, que destacan por el detalle en la ilustración del pelaje y las circunferencias con puntos, motivos que luego se pueden encontrar como referencias al felino (Fig. 5.2c y Fig. 6.1a y b). El más Ilamativo quizás de los felinos es el que Cardich (1979) describe para la cueva $6 \mathrm{~b}$ de El Ceibo (Fig. 5.2b). Con $150 \mathrm{~cm}$ de largo fue pintado de perfil en base a pintura plana y se insinúa un "débil sombreado" que genera cierta profundidad, posiblemente en acecho dado el tamaño de las patas y la exaltación de las garras. Cardich (1979) lo asocia a una especie extinta (Panthera onca mesembrina), ya que se encontraron restos de puma en las capas más profundas de El Ceibo. En el registro arqueológico de Cueva Túnel (LQM) se encontraron en estratigrafía diversos restos óseos de puma y un diente incisivo del felino extinto Panthera onca messembrina (Paunero et al., 2015). En algunos elementos óseos de puma se identificaron marcas coherentes con prácticas de descarne (Valiza Davis, 2021), lo que daría cuenta del consumo de estos animales por parte de las sociedades. En cuanto al arte rupestre, los felinos, son poco frecuentes (Paunero et al., 2005). La mayor parte de los motivos remiten a atributos felinos, como ciertas "rosetas", circunferencias de puntos que se interpretan como pisadas o los dibujos del pelaje, o líneas punteadas paralelas, que podrían recrear el patrón de puntos del pelaje de los pumas juveniles (Fig. $5.1 \mathrm{c} \mathrm{y}$ Fig. 6.1 a y b). Un solo caso presenta un nivel de detalle tal que es posible reconocer las garras y el posiblemente pelaje erizado (Fig. 5.2 a).

\begin{tabular}{|c|c|c|c|c|c|c|c|c|}
\hline \multirow{2}{*}{ Escenas } & \multirow{2}{*}{$\mathrm{n}$} & \multicolumn{7}{|c|}{ Elementos en escena } \\
\hline & & Antrop. & Zoo. Indet & Circ. & Circunf. & Guanaco & Línea & Óvalc \\
\hline Guanaco con circunferencia & 4 & & & 1 & 1 & 21 & 1 & 3 \\
\hline Guanaco con antropomorfo & 3 & 8 & 3 & & & 6 & 1 & \\
\hline Guanaco con guanaco & 7 & & 1 & & & 72 & & \\
\hline Guanaco con línea & 2 & & & & & 2 & 2 & \\
\hline Total & 17 & 8 & 4 & 1 & 1 & 101 & 4 & 3 \\
\hline
\end{tabular}

Tabla 2. Frecuencia de tipos de escena y subtipos de escenas que involucran guanacos y asociaciones con otros motivos.

Table 2. Frequency of scene types and scene subtypes involving guanacos and associations with other motifs. 

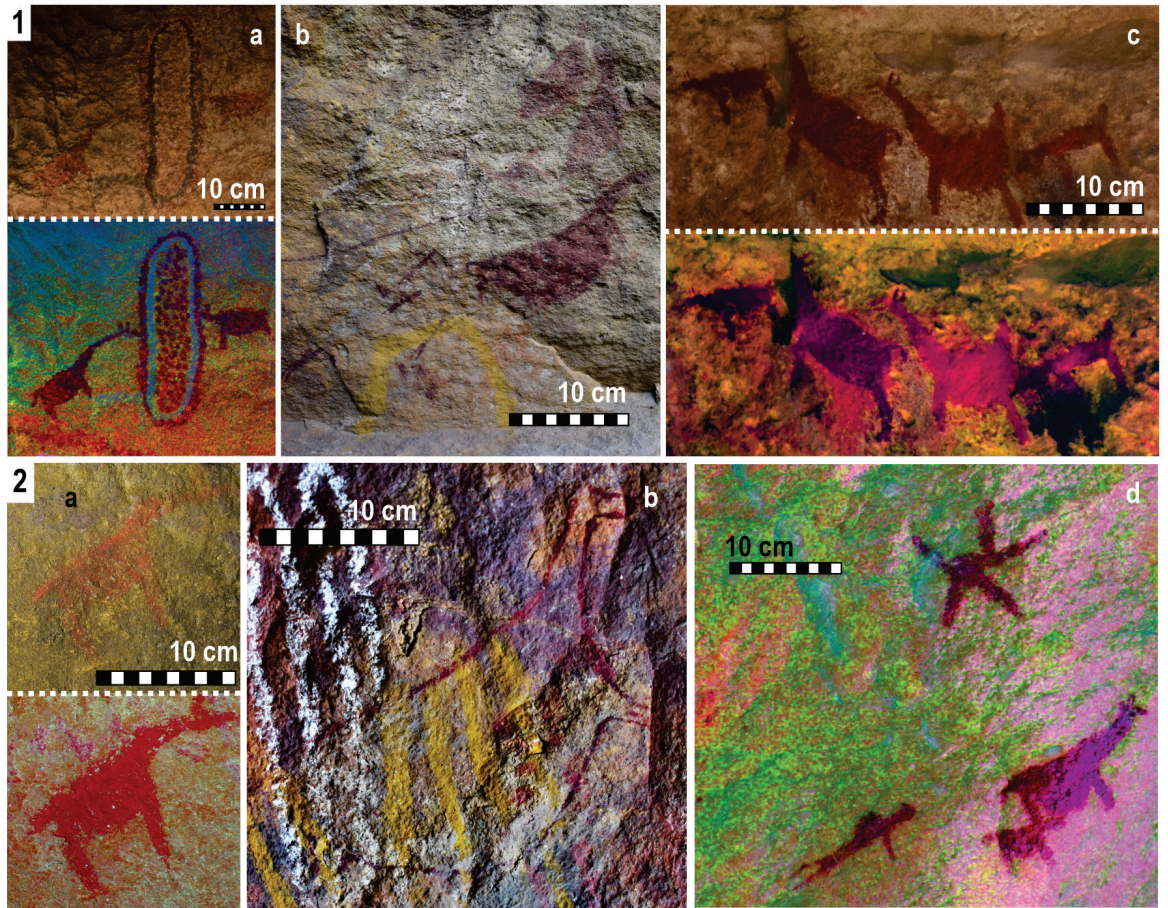

Figura 4. Tipo de motivo guanaco por sitio 1) Tipo Escena a. Cueva $\mathrm{H}$, fotografía original y filtro $\mathrm{crgb}$; $\mathrm{B}$. Cueva $G$, fotografía original; $C$. Cueva E, fotografía original y D-Strech, ybk y d. Cueva H, D-Strech, crgb, recorte de Guanaco con antropomorfo en escena; 2) Tipo Guanaco aislado. A. Cueva MDQ, fotografía original y D-Strech, yre; B. Cueva DF, fotografía original.

Figure 4. Guanaco motif type by site 1) Scene Type a. Cave H, original photograph and crgb filter; B. Cave G, original photograph; C. Cave $E$, original photograph and D-Strech, ybk and d. Cueva $H$, D-Strech, crgb, Guanaco cutout with anthropomorphic on stage; 2) Isolated Guanaco type. A. Cave $M D Q$, original photograph and $D$-Strech, yre; $B$. Cueva $D F$, original photograph.
En cuanto al posible ensamble felino-antropomorfo, Cardich (1979) destaca la presencia de un negativo de mano sobre el felino como señal de emoción y reflejo de sus creencias, sugiere la posible identificación con atributos del felino, describiendo de la siguiente forma "...Y conmovida su ánima, habría desarrollado, tal vez actitudes de raíz espiritual en torno al mismo..." (Cardich, 1979 p. 180).

Figura 5. Tipos de motivos asociados a felinos. 1) a. y b. Huella, Cueva LG, fotografía original; $C$. Óvalo con puntos, cueva DF, fotografía original 2) a. Cueva DF, fotografía original b. "Gran felino" cueva 6 de El Ceibo (Foto Fabio Vázquez); C. Cueva 6 felinos Localidad La reconquista (Foto gentileza de Fernando Ramírez Rozzi), D-Strech, Ids

Figure 5. Types of motifs associated with felines. 1) $a$. and b. Footprint, Cave LG, original photograph; C. Oval with dots, cave DF, original photograph 2) a. Cueva DF, original photograph b. "Big feline" cave 6 of El Ceibo (Photo Fabio Vázquez); C. Cueva 6 felinos Location La reconquista (Photo courtesy of Fernando Ramírez Rozzi), D-Strech, Ids
Si bien son dos contextos sumamente diferentes, podemos pensar cierto paralelismo entre la mano sobre el gran felino que detalla Cardich, y el testimonio de Musters (1871 [2016]) de la ceremonia de curación del niño, mediante la aplicación de pintura sobre una yegua blanca (Muster, 1871 [2016]; p247). Si la mano pintada sobre la yegua blanca, quita la enfermedad del niño, tal vez la mano sobre el felino opera en forma similar, otorgando o quitando propiedades de la interioridad
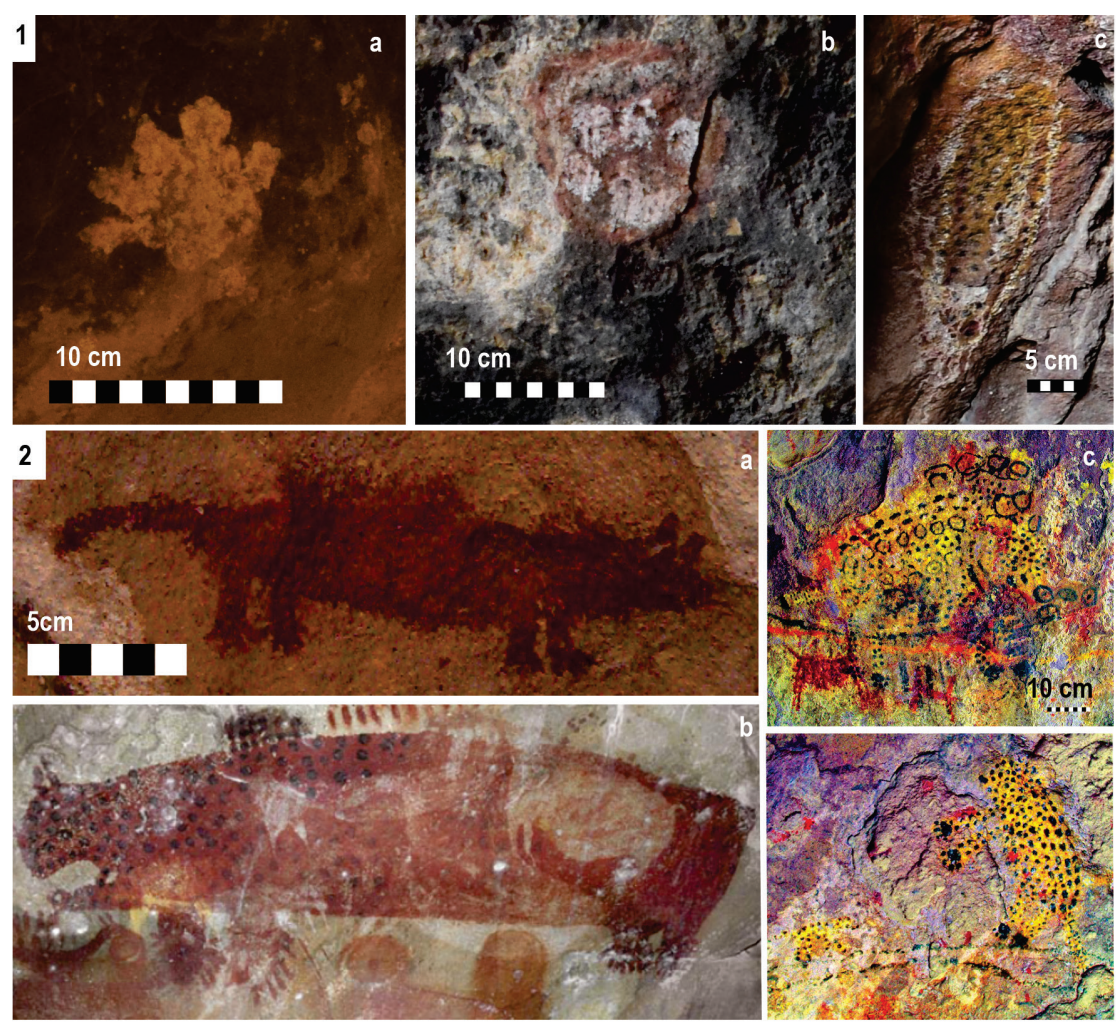

ISSN 1852-060X (impreso) / ISSN 1852-4826 (electrónico) 

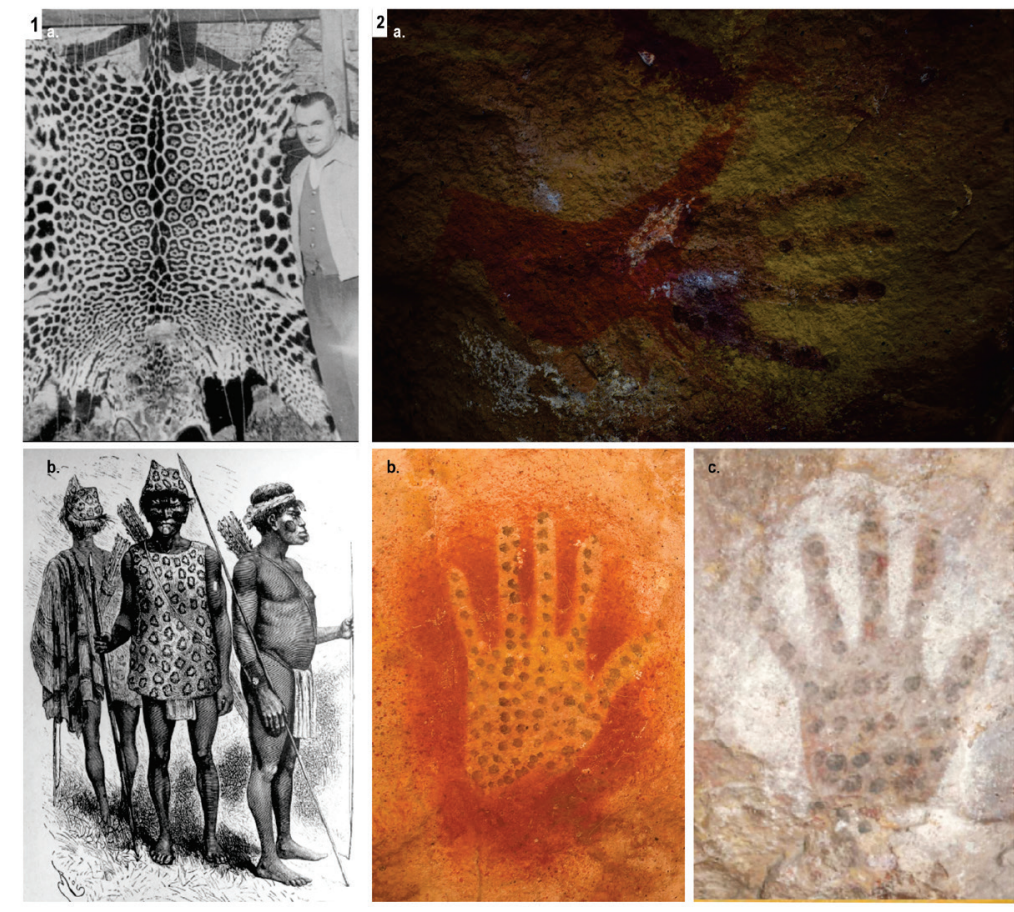

Figura 6. Imágenes alusivas al ensamble humanofelino 1) a. Piel expuesta de un jaguar en 1957 en provincia del Chaco (en Carden, 2008 p29); B. Guerreros chiriguanos del siglo XIX portando vestimentas confeccionadas con pieles de jaguar (en Pastor et al., 2015: p); 2) Negativo de manos con puntos, a. Sobre guanaco, Cueva DF; B. Cañadón de las columnas, Ea. La María; C. Cueva DF.

Figure 6. Images allusive to the human-feline assembly 1) a. Exposed skin of a jaguar in 1957 in the province of Chaco (in Carden, 2007 p29); $B$. Chiriguano warriors from the 19th century wearing clothing made with jaguar skins (in Pastor et al., 2015); 2) Negative of dotted hands, a. About Guanaco, Cueva DF; B. Cañadón de las columnas, Ea. La María; C. Cave DF. de ambas entidades, la humana y la felina. Musters no describe en detalle la forma de la pintura sobre la yegua, quizás podemos pensar en un flujo entre la técnica (estarcido, o aplicación plana de la pintura) y la acción de quitar/otorgar, tomar/ceder propiedades entre entidades o cosas. En el caso de LMQ, si bien no hemos registrado imágenes agrupadas de felinos y antropomorfos, hay un caso particular de negativos de manos con puntos negros dentro que se asocia a las pintas de color oscuro que presentan los felinos sobre el pelaje (Fig. 5.1 c; Paunero, 2009).

Para profundizar en esta relación entre manos, puntos y felinos, si bien no es propio de Patagonia recurriré al mito del runa-uturunco (Hombres tigres), ampliamente extendido en el noroeste y sierras centrales de nuestro país, descripto como una entidad no humana que goza de apariencia humana o viceversa (Fig. 6). Las recopilaciones lo describen como "un viejo indio que se revuelca en la piel de un tigre y se metamorfosea" (Quiroga, 1929: 2010). Los relatos también indican que una vez metamorfoseado el runa-uturunco socializaba con otros tigres y se apareaba con las hembras y que la única forma de distinguirlo era por las marcas de sus huellas de cinco dedos no de cuatro como el resto de los felinos. Rex Gonzalez recoge el testimonio de un poblador de Ambato que dice: "... el runa uturunco era un hombre que tenía piel de tigre. La usaba para sus hechicerías, se la ponía y estaba transformado en tigre..." (Gonzalez 1998: 319).

Estas descripciones del mito coinciden con los atributos de felinos que aparecen representados, tanto las pisadas como las imágenes alusivas a la piel y las manos humanas con rasgos de felino y al hecho que antropomorfos y zoomorfos muy rara vez aparecen representados juntos. Si bien no hay registros en Patagonia de figuras antropomorfas felinizadas como es el caso del noroeste argentino (Laguens y Gastaldi, 2008), podemos mencionar la presencia de las manos humanas con puntos como una posible combinación de propiedades en un ensamble que sea manos felinizadas.

Casamiquela (1958) describe canciones totémicas de felinos que detallan las manos y brazos pintados de los humanos que se identifican con ese tótem. La Canción del Tigre ${ }^{10}$ hace alusión al "brazo pintado" del puma, que el autor asocia a la voz araucana utilizada para la noción de tatuaje corporal. Estas observaciones rescatadas de los mitos y canciones totémicas en relación a los motivos rupestres mencionados (Fig. 6. 2 b y c) permite ver en los ensambles de figuras antropomorfas y felínicas, una especie de semejanza de exterioridad e interioridad, una falta de diferenciación en la exterioridad que puede suponer un cambio de forma o un intercambio de atributos. En el esquema que plantea Descola (2005) correspondería al totemismo.

\section{Palabras finales}

\section{Dificultades y despedida}

Analizar la agencia y ontología de la materia en restos arqueológicos plantea desafíos innegables, y estos desafíos son más agudos en la interpretación del arte rupestre de Patagonia. La dificultad es clara y evidente: no contamos aún con un conjunto de estudios sólido y sistemático que nos permita conocer ontologías de

\footnotetext{
10 "Canción del Tigre" Gaiawel, Gaiawel melen (derivados de tótem y canción) No es para jugar nuestro tótem, partía al medio el malón, el corazón de tire, del sol-tigre, brazo pintado. (traducción de Casamiquela, 1958 p. 306)
} 
cazadores recolectores patagónicos. Ese salto de fe (y de militancia) que implica tomar creencias y visiones como teorías sobre el mundo, si bien se presenta como una tarea enorme, también se ve como un horizonte de muchas posibilidades que puede ofrecer un campo heurístico más amplio que el determinismo ecológico.

¿Qué relación hay entre humanos, guanacos, felinos y cuevas? ¿Qué implica esa forma de relación mediada por la huella/vestigio de la mano/pata? Considerando lo que dice Cesar (1984), es como "sostener" la mano sobre la "naturaleza", es una forma de humanizar la naturaleza y trascender la dualidad. Una idea de flujo, de intercambio recíproco, entre humanos y no humanos. Implica algo en común, quizás una interioridad, que se puede intercambiar, o incluso quitar del otro para que pierda sus posibilidades de agencia, como el daño (la ferocidad del puma, la enfermedad del niño). Explorar supuestos entorno a la interioridad de los objetos, imágenes y lugares, es un punto de partida que puede enriquecer mucho las interpretaciones sobre las dinámicas de las sociedades cazadoras-recolectoras. No es improbable que alguna forma de interioridad haya sido asignada a las imágenes, alguna forma de agencia, afecto, incluso de una vida propia. Pensar las imágenes rupestres en términos de ensambles de atributos de pigmentos, agua, grasa, molienda, saliva y la boca humana, nos pone frente al producto de prácticas repetidas que implican memorias y afectos, vinculadas a otras actividades y lugares. La materialidad de las imágenes se torna una forma de romper con la "alienación de los territorios no familiares". Las manifestaciones rupestres se pueden convertir en la continuidad de la vida cotidiana en la discontinuidad que puede significar la tensión de una situación crítica y cambiante, como el desplazamiento y el enfrentamiento a lo desconocido, facilitando la rutinización de la vida social (Laguens 2009) de las sociedades cazadoras-recolectoras.

En el caso particular de las manifestaciones rupestres de La María, las categorías de ontología animista y ensamble, se muestran sumamente prometedoras para indagar en torno a sus atributos, lejos de la ilusión de las apariencias de las formas. Pensar como ensambles de propiedades las imágenes de guanacos, antropomorfos, felinos y negativos y sus relaciones, nos permite desprendernos de los contenidos atribuidos sólo a lo que vemos y nos abre un campo de posibilidades para profundizar en todas las materialidades y agencias involucradas. En cuanto a estos ensambles, queda como tarea a futuro reflexionar sobre el ensamble que incluye a los motivos no figurativos ¿En relación a que atributos los podemos pensar? Esta apertura al final de la conclusión, lejos de ser un retroceso se presenta como una pasó adelante en la indagación. Existe la posibilidad que como dice Descola (2005), no se traté de una ontología encasillada en uno de los cuatro modos, sino que convivan simultáneamente aspectos de diferentes esquemas ontológicos, lo cual hoy resulta en distintas lecturas posibles del mismo registro arqueológico. Desde esta perspectiva nunca vamos a encontrar indicadores, ya que justamente al pensar relacionalmente, no hay una relación unívoca entre materialidad/indicador/interpretación. Nada indica nada. Las cosas cobran sentido en relación. Entonces, no sería tanto la falta de indicadores concluyentes, sino que las manifestaciones, sus propiedades y relaciones reconocidas no me permiten ser concluyente, pero si arriesgar ciertas aproximaciones.

Retomar el interés por el animismo entonces, tiene poco que ver con tratar de determinar cómo pensaban aquellos cazadores sobre el mundo, sino con cómo nosotres podríamos pensar de manera tal de concebir el mundo en el modo que ellos lo hacían (Henare, 2007) y como se inscribe en las manifestaciones rupestres. No se trata de indagar qué significaron para sus creadores, sino buscar algo que nos interpele, algo que nos haga pensar sobre nuestras categorías y formas de describir y construir mundos y pasados. Algo pues que, como decía Romeo Cesar (1984: 62), "emergiendo de la piedra pintada nos involucre y nos pregunte sobre nosotros mismos".

\section{Agradecimientos}

Especialmente al Dr. Andrés Laguens por la confianza y el aliento a participar del presente dossier. A Rafael Paunero por las reflexiones previas y la humanización de la arqueología. Ariel Frank, Catalina Valiza Davis y Marcelo Garivatti por la revisión concienzuda y las sugerencias bibliográficas y a Fernando Ramírez Rozzi por las fotos facilitadas. A las evaluaciones anónimas que enriquecieron este trabajo. Todo lo expresado anteriormente es mi absoluta responsabilidad y opinión.

\section{Bibliografía consultada}

Acevedo, A. (2017). Arte, composición visual y paisaje: un estudio de la producción rupestre de los grupos cazadores-recolectores de la región Extremo Sur del Macizo del Deseado. Provincia de Santa Cruz, Argentina (Tesis doctoral) Facultad de Filosofía y Letras. Universidad de Buenos Aires.

Acevedo, A., \& Fiore, D. (2020). Imágenes, códigos y comunicación: un análisis del arte rupestre en el Extremo Sur del Macizo del Deseado (Patagonia, Argentina). Arqueología, 2(26), 127-155. https://doi.org/10.34096/ arqueologia.t26.n2.5835

Acevedo, A., Fiore, D., \& Franco, N. V. (2013). Imágenes en las rocas: uso del espacio y construcción del paisaje mediante el emplazamiento de arte rupestre en dos regiones de Patagonia centromeridional (Argentina). Espacio, Tiempo y Forma, 6, 17-53.

Alberti, B., \& Marshall, Y. (2009). Animating archaeology: local theories and conceptually open-ended 
methodologies. Cambridge Archaeological Journal, 19(3), 344-356.

Alberti, B. \& Jones, A.M. (2013). Archaeology after Interpretation. En B. Alberti (Ed.), Archaeology after Interpretation. Returning Materials to Archaeological Theory (pp. 15-35). Left Coast Press Inc.California.

Alberti, B. (2016). Archaeologies of Ontology. Annual Review of Anthropology, 45, 163-179.

Arrigoni, G. (1996). El arte rupestre del cañadón Sin Nombre. Cueva de los Felinos. (Santa Cruz). En Arqueología solo Patagonia. Ponencias de la Segunda Jornada de Arqueología de Patagonia. Editado por J. Gómez Otero, pp. 131-141. CENPAT-CONICET. Puerto Madryn.

Aschero, C. (1988). Pinturas rupestres, actividades y recursos naturales: un encuadre arqueológico. En Arqueología Contemporánea Argentina, Actualidad y Perspectivas. Editado por H. Yacobaccio, pp. 109-145. Ediciones Búsqueda. Buenos Aires.

Aschero, C. (1996). ¿Dónde van esos guanacos? En Arqueología. Solo Patagonia. Ponencias de las II Jornadas de Arqueología de la Patagonia. Editado por J. Gómez Otero, pp. 153-152. Puerto Madryn.

Blanco, R. V. (2015). El arte rupestre en los Macizos del Deseado y Somuncurá: la producción de grabados y pinturas entre cazadores-recolectores desde el Holoceno medio. (Tesis doctoral) Facultad de Ciencias Naturales y museo. Universidad Nacional de La Plata.

Carden, N. (2007). Estudio de las Manifestaciones Rupestres de la meseta central de santa cruz. El área de los zanjones blanco y rojo al sur del rio deseado. Facultad de Ciencias Naturales y Museo. Universidad Nacional de La Plata.

Bodei, R. (2013). La vida de las Cosas. 1er Edición. Amorrortu editores. Buenos Aires-Madrid.

Cardich, A. (1979). A propósito de un motivo sobresaliente en las pinturas rupestres de El Ceibo (Provincia de Santa Cruz, Argentina). Relaciones de la Sociedad Argentina de Antropología, XIII: 163-182.

Casamiquela, R. (1958). Canciones totémicas araucanas y gununakena (tehuelches septentrionales). Revista Museo de La Plata, IV: 293-314. Universidad Nacional de La Plata. La Plata.

Casamiquela, R. (1960). Sobre las significación del arte rupestre nordpatagónico. Cuadernos del sur, Instituto de Humanidades. Universidad nacional del sur. Bahía blanca.
Casamiquela, R. (1977). Posibles raíces patagónicas en creencias araucanas. Relaciones de la Sociedad Argentina de Antropología, XI: 107-114.

Cesar, R. (1984). La mano y la máscara. Meditaciones sobre un motivo del arte rupestre patagónico. En: Cuadernos patagónicos. Universidad nacional de la Patagonia San Juan Bosco.

Criado Boado, F. (1999). Del terreno al espacio: planteammientos y perspectivas para la arqueología del paisaje. CAPA, 6: Pp: 1-58.

Cueto, M.E., Frank A.D. \& Castro A. (2015). A technomorphological and functional study of Late Pleistocene and Middle Holocene lithic assemblages from Patagonia Argentina. Quaternary International, 442, 67-79.

Descola, P. (2005). Antropología de la naturaleza. IFEA, Lima.

Dobres, M.-A. \& J.E. Robb, (2005). Doing' agency: introductory remarks on methodology. Journal of Archaeological Method and Theory 12(3), 159-66.

Dowding, K. 1996. Power. Buckingham: Open University Press.

Fiore, D. (2020). The Art of Making Images. Journal of Archaeological Method and Theory.

Fowler, C. (2017). Tipologías relacionales, teoría de ensambles y entierros de la Edad de Bronce Temprana. Cambridge Archaeological Journal 27

Franchomme, J. M. (1991). L'art Rupestre de Patagonie: quelques sites Prehistoriques du Plateau Central, Province de Santa Cruz, Argentine. (Tesis doctoral inédita), Universidad de París X. Nanterre, Francia.

Frank, A.D. (2011). Tratamiento térmico y manejo del fuego en sociedades cazadoras-recolectoras de la Meseta Central de Santa Cruz. (Tesis doctoral inédita), Facultad de Ciencias Naturales y Museo, Universidad Nacional de La Plata, Argentina.

Gardner, P. (2004). Introduction: social agency, power, and being human. En Agency Uncovered Archaeological perspectives on social agency, power, A. Gardner, pp. 1-19. Cavendish Publishing Limited.

Gell, A. (2016). Arte y Agencia. Una teoría antropológica. Sb. Editorial; 1st ed. Buenos Aires.

Guichón, F. (2018). Redes de información durante el holoceno medio y tardío en patagonia meridional 
estudio de las representaciones rupestres en la cuenca del Lago Cardiel y sur de la Meseta del Strobel (Tesis doctoral) Universidad de Buenos Aires- Facultad de Filosofía y Letra.

Gonzalez Dubox, R. E., Frank, A., Cueto, M., \& Paunero, R. (2021). Manifestaciones rupestres situadas: tipología y distribución de las pinturas de la maría quebrada, provincia de santa cruz. Cuadernos Del Instituto Nacional de Antropología y Pensamiento Latinoamericano - Series Especiales, 9(1), 225-244.

Gonzalez, A.R. (1998). Cultura La Aguada. Arqueología $y$ diseños. Filmediciones valero. Buenos Aires.

Gonzalez, A.R. (2000). Tiestos Dispersos: Voluntad Y Azar En La Vida De Un Arqueólogo. Buenos Aires: Emecé.

Hartley, R. J. (1992). Rock Art on the Northern Colorado Plateau: Variability in Content and Context. Avebury. Aldershot.

Henare A. (2007). Thinking through things. Theorising artefacts ethnographically. Editado por Amiria Henare, Martin Holbraad y Sari Wastell. Routledge, Londres.

Ingold, T. (2000). The perception of the environment. Essays in livelihood, dwelling and skill. London: Routledge.

Jordan, P. (2004). Examining the role of agency in huntergatherer cultural transmission. En Agency Uncovered Archaeological perspectives on social agency, power, A. Gardner, pp. 107-134. Cavendish Publishing Limited.

Laguens, A. G. \& M. R. Gastaldi. (2008). Registro material, fisicalidad, interioridad, continuidad y discontinuidad: posiciones y oposiciones frente a la naturaleza y las cosas. En Puentes hacia el pasado. Reflexiones teóricas en arqueología, editado por Andrés Troncoso y Donald Jackson, Editorial Lom, Chile.

Laguens, A. (2009). De la diáspora al laberinto: Notas y reflexiones sobre la dinámica relacional del poblamiento humano en el centro-sur de Sudamérica. Arqueología Suramericana, 5(1), 26.

Laguens, A. (2014). Contextos inestables: ontologías relacionales y entornos domésticos en el noroeste andino de Argentina En: Archaeology after interpretation. Returning materials to archaeological theory Ed. por B. Alberti, A. Jones y J. Pollard.

Laguens, A. (2018). Mimesis, citas y copias: reflexiones sobre los modos de hacer y ser en soto, Córdoba, argentina, en tiempos pre-coloniales. En XII Jornadas de Investigadores en Arqueología y Etnohistoria del Centro
Oeste del país.

Latour, B. (2012). Nunca fuimos modernos. Editorial Siglo XXI, Buenos Aires.

Laming-Emperaire, A. (1962). La signification de I'art rupestre paléolithique. Picard, Paris.

Leroi-Gourhan, A. (1968). The Art of Prehistoric Man in Western Europe. Thames and Hudson. London.

Leroi-Gourhan, A. (1971). El gesto y la palabra. Publicaciones de la Universidad Central de Venezuela, Caracas.

Lucas, G. (2012). Cap. 4: La cultura materializada. En Understanding the Archaeological record, Cambridge University Press. Pp 124-168.

Molina, M. (1976). Patagónica. Prehistoria, Tradiciones y Mitología. Comodoro Rivadavia: Librería Ateneo Saleciano, Universidad de la Patagonia San Juan Bosco.

Moreno, Francisco P. (1879) [1969]. Viaje a la Patagonia Austral. 1876-1877. Ediciones Solar, Buenos Aires.

Musters, G.C. (1871) [2016] Vida Entre los Patagones. Un Año de Excursiones por Tierras no Frecuentadas Desde el Estrecho de Magallanes hasta el Río Negro. 2 da edición. Editorial Continente. Buenos Aires.

Nazar, D.C. y De la Fuente G.A. (2016). Remembranzas ancestrales. Conflicto y violencia en las rocas de La Tunita (Sierra de Ancasti, Catamarca) En: F. Oliva, A. M. Rocchietti y F. Solomita Banfi (eds.), Imágenes rupestres, lugares y regiones (pp. 159-168). Rosario: CEAR, Facultad de Humanidades y Artes, Universidad Nacional de Rosario.

Pastor, S., Recalde, A., Tissera, L., Ocampo, M., Truyol, G., \& Chiavazza-Arias, S. (2015). Chamanes, Guerreros, Felinos: Iconografía de Transmutación en el Noroeste de Córdoba (Argentina). Boletín SIARB, 29, 71-85.

Paunero, R. (1992). Manos pintadas en negativo: un ensayo de experimentación. Revista de estudios Regionales - CEIDER 9: 47-68.

Paunero, R. (2000). Relevamiento, arte rupestre y sectorización de la localidad La María. En L. Miotti, R. Paunero, M. Salemme y R. Cattáneo (Comps.), Guía de Campo de la Visita a las Localidades Arqueológicas. Taller Internacional La Colonización del Sur de América Durante la Transición Pleistoceno/Holoceno (pp. 104108). La Plata: Edición Nacional.

Paunero, R. (2009). El Arte Rupestre Milenario De Estancia La María, Meseta Central De Santa Cruz. City 
Bell: Estudio Denis.

Paunero, R.S., Frank A. D., Skarbun F., Rosales G., Zapata G., Cueto M., Paunero M. F., Martínez, D., López R., Lunazzi N. \& Del Giorgio. (2005). Arte rupestre en Estancia La María, Meseta Central de Santa Cruz: sectorización y contextos arqueológicos. Relaciones de la Sociedad Argentina de Antropología, XXX, 147-168.

Paunero, R.S. y C. Valiza Davis (2013). Marcado perimetral sobre fémur de Lama gracilis en Cueva Túnel de La María, Santa Cruz, Argentina. XVIII Congreso Nacional de Arqueología Argentina, pp 546.

Quiroga, A. (1929). Folklore calchaquí. En: Revista de la Universidad de Buenos Aires, sección VI, tomo V: 1-319. Buenos Aires

Schobinger, J. (1956). El Arte Rupestre de la provincia del Neuquén. Anales de Arqueología y Etnología. TXII: 115-227.

Re, A. (2010). Representaciones rupestres en mesetas altas de la provincia de Santa Cruz (Tesis doctoral). Facultad de Filosofía y Letras. Universidad de Buenos Aires.

Reinach, S. (1903). L'Art et la Magie apropos des peintures et des gravures del'Age du Renne. En L'Anthropologie, XIV, 257-266.

Schobinger J. y C. Gradin. (1985). Arte Rupestre de la
Argentina. Cazadores de la Patagonia y Agricultores Andinos. Ediciones Encuentro. Madrid.

Skarbun, F. (2009). Análisis de los conjuntos líticos del sitio La Mesada, Localidad Arqueológica La María, Meseta Central de Santa Cruz. En M.C. Salemme, F. Santiago, M. Álvarez, E. Piana, M. Vazquez y M.E. Mansur (Eds.), Arqueología de Patagonia: una Mirada desde el último confin (pp. 1177-1194). Utopías, Ushuaia.

Tilley C. (1991). Material Culture and Text: the art of ambiguity. Routledge. London

Tylor, E.B. (1871) [1971] Cultura primitiva: Los orígenes de la cultura. Ayu. Lima.

Troncoso, A. (2014). Relacionalidad, prácticas, ontologías y arte rupestre en el centro norte de Chile (2000 a.C. a 1.540 d.C.). Revista de Arqueología 27(2): 64-87.

Valiza Davis, C. (2021). Zooarqueología de cazadoresrecolectores que habitaron la Meseta Central de Santa Cruz durante la transición Pleistoceno-Holoceno. Tesis doctoral, Facultad de Ciencias Naturales y Museo. UNLP.

Wobst M. (1977). Stylistic Behavior and Information Exchange. En Papers for the Director: Research Essays in Honor of James B. Griffin. University of Michigan. Museum of Anthropology: Anthropological Papers 61, editado por C.E. Cleland, pp 317-342, Ann Arbor, Michigan. 